\title{
The ethicolegal framework relevant to human faecal microbiota transplants in South Africa: Part 3. Stool as a 'drug' or medicine
}

\author{
M Labuschaigne, ${ }^{1}$ BA Hons, MA, DLitt, LLB, LLD; M Slabbert, ${ }^{1}$ BA Hons, HED, BProc, LLB, LLD; S Budree, ${ }^{2}$ MB ChB, DCH, FC Paed (SA), \\ Cert Gastroenterology (SA) Paed; E Hoosien, ${ }^{3}$ MB ChB, MMed Path (Med Microbiol), DTM\&H; A Brink, ${ }^{4}$ MB ChB, MMed (Clin Microbiol); \\ M Blockman, ${ }^{5}$ BPharm, MB ChB, PG Dip Int Res Ethics, MMed (Clin Pharmacol) \\ ${ }^{1}$ Department of Jurisprudence, School of Law, University of South Africa \\ ${ }^{2}$ Department of Paediatrics, Faculty of Health Sciences, University of Cape Town, South Africa; and OpenBiome, Cambridge, Mass., USA \\ ${ }^{3}$ Clinical Microbiology Department, Ampath Laboratories, Centurion, South Africa \\ ${ }^{4}$ Division of Medical Microbiology, Department of Pathology, Faculty of Health Sciences, University of Cape Town, South Africa; and National \\ Health Laboratory Service, Cape Town, South Africa \\ ${ }^{5}$ Division of Clinical Pharmacology, Department of Medicine, Faculty of Health Sciences, University of Cape Town, South Africa
}

Corresponding author: M Labuschaigne (slabbmn@unisa.ac.za)

\begin{abstract}
The purpose of this article, the last in a series of three exploring the legal framework for the regulation of faecal microbiota transplantation (FMT) in South Africa (SA), is to determine the regulatory framework that applies to microbial-based treatments involving a level of manipulation that exceeds that of basic stool transplantation, e.g. processed FMT-derived products in capsule form. The article highlights the legal requirements for the registration of these products as biological medicines in SA law. Although human stool banks are not regulated in terms of the National Health Act 61 of 2003 (NHA) and regulations, the earlier articles point out that human stool fits the definition of human tissue and human biological material as defined by the NHA. For this reason, stool banks should be considered tissue banks in terms of the NHA and regulations. Healthcare practitioners and researchers involved in FMT banking and transplantation should strive to comply with these regulations in the absence of clear legal direction at present.
\end{abstract}

S Afr Med J 2020;110(8):819-821. https://doi.org/10.7196/SAMJ.2020.v110i8.15070

In two previous articles in this issue of $S A M J$, the legal regulation of human faecal microbial transplantation (FMT) has been addressed. ${ }^{[1,2]}$ In those articles, the important role of FMT as an effective treatment for recurrent Clostridioides difficile infection (CDI), which is a major cause of morbidity and mortality, was discussed. The articles also emphasised the uncertainty regarding the ethicolegal regulation of microbiome-based therapy and research in a legal context in South African (SA) law. The second article in the series addressed the issue of the categorisation of human stool as human tissue in terms of the National Health Act 61 of 2003 (NHA), as well as the legal requirements for a stool bank. In this article, the focus will turn to processed human stool as medicine or medical treatment.

The nature of FMT is unique and different from conventional medicines or therapies. It may include characteristics and components of a 'health service' in terms of the NHA, which includes medical treatment, or a 'medicine' as described in the Medicines and Related Substances Act 101 of 1965 (MRSA). Each of these has different legal and ethical considerations, depending on the nature of the procedure.

If administered orally by way of swallowing capsules containing processed faecal microbial material, this type of microbial treatment arguably enters the realm of the registration of medicines. The administration of minimally processed microbial matter via nasoduodenal tube or colonoscopy would arguably resemble medical treatment. The confusion regarding the exact nature of an FMT also appears from the US Food and Drug Administration (FDA)'s position on the issue, which has shifted a few times in recent years. ${ }^{[3]}$ The FDA currently classifies FMTs as a drug (e.g. a live biotherapeutic product), a position it took since May 2013, subject to enforcement discretion of not requiring an Investigational New Drug (IND) application for doctors performing the procedure and stool banks providing faecal matter for patients with CDI unresponsive to standard therapies. ${ }^{[3,4]}$

In March 2016, however, the FDA published a draft guidance document that requires stool banks to submit an IND application to obtain and distribute stool to doctors. However, the IND would not be applied in the case of doctors collecting and screening donor stool and performing the procedure, or for entities such as hospital laboratories that collect and prepare FMT products 'solely under the direction of licensed health care providers' for use by the patients of the provider. ${ }^{[5]}$ This draft guidance was never implemented and therefore never superseded the 2013 guidance, owing to significant objection from clinicians and patient advocates. More recently in June 2019 , the FDA issued a safety alert on the risk of serious infections caused by multidrug-resistant organisms related to the investigational use of faecal microbiota for transplantation, following the death of an immunocompromised patient who received an investigational FMT.

Different regulatory systems may regulate FMT as both a product and a procedure that combines different approaches for the treatment of drugs, blood and human tissue for transplantation, or view it as part of the practice of medicine (e.g. clinical treatment). ${ }^{[3]}$ The regulatory pathway would depend on the exact composition of the FMT and the relevant formulations or levels of manipulation of the stool, which may range from basic frozen stool to capsules containing frozen stool, or lyophilised powder or defined microbial consortia. ${ }^{[5]}$ 
Stool-based products containing specific bacterial strains aimed at treating specific diseases involve a higher level of manipulation and a more target-specific approach. The level of manipulation of the stool is critical in the determination of the relevant regulatory pathway, as FMTs involving material that is 'more than minimally manipulated' may require registration as a medicine (e.g. a biological), as is the case in the USA. Human cells, tissue, and cellular and tissue-based products not meeting these criteria, however, are also subject to the good tissue practice requirements and will in addition be regulated as drugs, biologicals or devices under section 351 of the Public Health Services Act and Title 21 of the Code of Federal Regulations (1271.20). ${ }^{[6]}$

In the most elementary FMT procedure, faeces are homogenised in a liquid buffer such as saline or glycerol - this indicates minimal manipulation. The FDA's definition of 'minimal manipulation' refers to 'processing that does not alter the relevant biologic characteristics of cells or tissue. ${ }^{\left[{ }^{[6]}\right.}$ According to Hoffmann et al. ${ }^{\left[{ }^{[3]}\right.}$ the degree of manipulation of stool may vary as follows from the least to the most manipulated: (i) fresh stool transferred from an individual donor; (ii) frozen filtered stool from a stool bank; (iii) concentrated stool microbiota in capsule form; (iv) biologically sourced, purified microbial groups of specific bacterial strains; and $(v)$ cultured bacterial mixture delivered in oral pill form.

The first two, $(i)$ and (ii), will be applicable if human stool is treated as tissue, as discussed in our first article in the series of three. The last two, (iv) and (v), will be regarded as highly manipulated stool-derived products, and a different regulatory framework will therefore apply to these products compared with that if basic stool was classified as tissue. The classification of (iii) is less clear. FMT capsules may contain the same faecal slurry as is administered via colonoscopy or nasogastric tube, pointing to material that is minimally manipulated, as there is no additional processing of the material, except aliquoting the material into the capsules. This position is very different from capsular administration, generally considered a form of upper gastrointestinal tract administration. Even if the faecal donation is not manipulated, the faecal material still requires careful testing and preparation. In view of this dilemma, we argue that a South African Health Products Regulatory Authority (SAHPRA) determination is urgently needed in order to extend oversight over this area, requiring, for example, registration of the person or entity preparing FMT products and stipulating standards for testing.

\section{Oral administration of faecal microbiota}

Trial sites in the USA and Canada are currently enrolling patients for clinical trials involving freeze-dried oral FMT capsules that contain healthy gut bacteria. ${ }^{[7]}$ The THRIVE study, a first global study of FMT in paediatric malnutrition as a small phase I study that will investigate whether faecal transplantation may assist severely malnourished children who fail to develop even after their nutritional needs are met, is worth mentioning. ${ }^{[8]}$ Any medicine containing processed faecal matter that will be distributed and sold in SA should comply with the requirements for the registration of medicines in terms of the MRSA. Since the FDA considers FMT to be a biological medicine, it is necessary to consider the requirements regarding biological medicines in SA.

The SAHPRA, which has been established to replace the Medicines Control Council, oversees the regulation of health products, which include medicines, medical devices, in vitro diagnostic tests and devices, radiation-emitting products, and devices used in healthcare and industry.
SAPHRA's General Information Guideline of May 2019, titled 'Guidance for the Submission of the South African CTD/eCTD General \& Module 1, ${ }^{[9]}$ provides recommendations for applicants preparing a common technical document for the registration of medicines for submission to SAHPRA. Legislation requires that every medicine is registered with SAHPRA before it may be sold or marketed ${ }^{[10]}$ (also see the National Department of Health's 2006 Guidelines for Good Practice in the Conduct of Clinical Trials $\left.{ }^{[11]}\right)$. An application for the registration of a medicine should therefore be submitted for evaluation and approval.

The sale of medicine that is subject to registration but not registered is prohibited in terms of section 14(1) of the MRSA. Section 14(4) of the MRSA provides an exception where such medicine is compounded in the course of the carrying on of his or her profession by inter alia a medical practitioner for a particular patient, in a quantity not greater than that required for treatment as determined by such medical practitioner. A particular substance must be used relatively widely for therapeutic purposes and not only on a 'single occasion' in order for the substance to qualify as a 'medicine' in terms of the MRSA. ${ }^{[12]}$

The MRSA defines a medicine in section 1 as:

'any substance or mixture of substances used or purporting to be suitable for use or manufactured or sold for use in -

(a) the diagnosis, treatment, mitigation, modification or prevention of disease, abnormal physical or mental state or the symptoms thereof in man; or

(b) restoring, correcting or modifying any somatic or psychic or organic function in man, and includes any veterinary medicine.'

Biological medicines, a highly specialised class or type of medicine, produced using living organisms, are complex protein structures typically much larger than traditional chemical medicines, and are mostly administered by injection. Biological medicines are more advanced than conventional therapies and provide prescribers with enhanced tools for treating patients. ${ }^{[13]}$ The MRSA does not define a biological medicine, but SAHPRA's website describes biological medicines as products 'produced from living organisms or contain components of living organisms. ${ }^{[14]}$ Biological medicines include 'a variety of products derived from human, animal or microorganisms by using biotechnology' Types of biological medicines include vaccines, blood, blood components, biotherapeutics, biosimilar and recombinant proteins. Biological products may contain proteins that control the action of other proteins and cellular processes, genes that control production of vital proteins, modified human hormones, or cells that produce substances that suppress or activate components of the immune system. ${ }^{[14]}$

The above understanding of biological medicines would arguably include faecal material that is manipulated for oral administration via capsule and other routes of administration (such as an enema FMTderived product). Since the MRSA requires that SAHPRA shall register every medicine before it may be sold and marketed, an application for the registration of a medicine should be submitted for evaluation and approval in accordance with SAHPRA's General Information Guideline, ${ }^{[9]}$ as well as the Clinical Guideline. ${ }^{[15]}$ Applications for registration of a medicine for use in humans are divided into different types for the determination of fees and allocation to reviewers for evaluation. As such, a biological medicine is one of the types of medicines applicable. It is a legal requirement that data submitted for evaluation, by the applicant, should substantiate all clinical claims and should meet the technical requirements of quality, safety and efficacy. SAHPRA refers to international guidelines to be read in 
conjunction with the SA guidelines. In particular, reference is made to the International Conference on Harmonization of Technical Requirements for Registration of Pharmaceuticals for Human Use $(\mathrm{ICH}),{ }^{[16]}$ the mission of which is to achieve greater harmonisation to ensure that safe, effective and high-quality medicines are developed and registered in the most resource-efficient manner, as well as to the European Medicines Agency. ${ }^{[17]}$

The ICH promotes public health, prevents unnecessary duplication of clinical trials in humans, and minimises the use of animal testing without compromising safety and effectiveness. ${ }^{[16]}$ Therefore, any applicant for the registration of a medicine must ensure that the technical requirements of quality, safety and efficacy of the product for the purposes for which it is intended have been met. After submission of the relevant administrative steps for the registration of a medicine (which includes biological medicine), these biological medicines (containing or derived from living materials) require primary evaluation by the Biological Medicines Committee, in addition to other committees of SAHPRA. The Biological Medicines Evaluation and Research Unit (BMERU), a sub-unit of medicines evaluation within SAHPRA, is tasked with the evaluation of applications for registration of biological medicines.

SAHPRA may choose to accept, defer or reject the application. Should the application be deferred, the applicant will be required to produce additional information and re-submit the application for approval. Once the application is accepted, the biological medicine is registered with SAHPRA and may be sold and marketed.

Failure to register an FMT in the prescribed manner, accepting that it falls within the scope of a biological medicine, would constitute a contravention of section 14(1) of the MRSA and hence an offence in terms of section 29 , punishable by virtue of section 30 by a fine or imprisonment for a period not exceeding 10 years.

\section{Microbiota-based products as probiotics?}

For the purpose of this article, it is necessary to consider whether FMT is more aligned with probiotics than a biological medicine. One major difference between FMT and probiotics is that the former graft in a patient's gut after administration, whereas the latter usually do not. Probiotics are not licensed to treat specific disease indications, and have not undergone phase I, II and III efficacy trials. In the USA, FMT-derived products are currently undergoing these efficacy trials. Probiotics in SA are regulated by SAPHRA in terms of the January 2020 Complementary Medicines - Discipline-Specific Safety and Efficacy guideline, ${ }^{[18]}$ the aim of which is to provide clear guidance with regard to the safety and efficacy requirements for registration of discipline-specific complementary medicines in SA in the common technical document format, in order to ensure that the levels of evidence for safety and efficacy are rigorous enough to protect public health and maintain consumer confidence. ${ }^{[18]}$ Not only are there clearly very few commonalities between FMT-derived products and probiotics, but their regulatory frameworks are also different. ${ }^{[19]}$

\section{Conclusions}

The purpose of this article was to explore the regulatory framework that applies to microbial-based treatments involving a level of manipulation that exceeds that of basic stool transplants, for example concentrated stool microbiota in capsule form. The article highlights the legal requirements for registration of these products as biological medicines in SA law. The article also concludes that FMT-derived products have few similarities to probiotics. This discussion is an addition to the previous article, which analyses the legal requirements relating to the use and transplantation of stool as part of human tissue regulation under the scope of chapter 8 of the NHA and regulations. Although human stool banks are not regulated in terms of the NHA and regulations, the previous article points out that human stool fits the definition of human tissue and human biological material as defined by the NHA. For this reason, stool banks could be considered as tissue banks in terms of the NHA and regulations and should strive to comply with these regulations in the absence of clear legal direction at present.

\section{Declaration. None.}

Acknowledgements. None.

Author contributions. Equal co-authors.

Funding. None.

Conflicts of interest. SB is employed by Finch Therapeutics, Somerville, Mass., USA, a company developing microbial therapies related to the treatments described in these articles.

1. Labuschaigne M, Slabbert M, Hoosien E, et al. The ethicolegal framework relevant to human faecal microbiota transplants in South Africa: Part 1. A legal vacuum. S Afr Med J 2020;110(8):812-815. https:// doi.org/10.7196/SAMJ.2020.v110i8.14563

2. Labuschaigne $M$, Slabbert $M$, Hoosien $E$, et al. The ethicolegal framework relevant to human faecal microbiota transplants in South Africa: Part 2. Human stool as tissue? S Afr Med J 2020;110(8):816-818. https://doi.org/10.7196/SAMJ.2020.v110i8.15069

3. Hoffmann DE, Palumbo FB, Ravel J, Rowthorn V, von Rosenvinge E. A proposed definition of microbiota transplantation for regulatory purposes. Gut Microbes 2017;8(3):208-213. https://doi.org/10.1080/1949 0976.2017.1293223

4. US Food and Drug Administration. Enforcement policy regarding investigational new drug requirements for use of fecal microbiota for transplantation to treat Clostridium difficile infection not requirements for use of fecal microbiota for transplantation to treat Clostridium difficile infection not
responsive to standard therapies: Guidance for industry. July 2013. https://www.fda.gov/regulatoryresponsive to standard therapies: Guidance for industry. July 2013. https://www.fda.gov/regulatory-
information/search-fda-guidance-documents/enforcement-policy-regarding-investigational-new-drug-

requirements-use-fecal-microbiota (accessed 20 October 2019).
5. US Food and Drug Administration. Enforcement policy regarding investigational new drug requirements for use of fecal microbiota for transplantation to treat Clostridium difficile infection not responsive to standard therapies: Draft guidance for industry. March 2016. https://www.fda.gov/regulatoryinformation/search-fda-guidance-documents/enforcement-policy-regarding-investigational-new-drugrequirements-use-fecal-microbiota-0 (accessed 20 October 2019).

6. US Food and Drug Administration. Minimal manipulation of human cells, tissues, and cellular and tissuebased products: Draft guidance for industry and Food and Drug Administration staff. 23 December 2014 https://www.federalregister.gov/documents/2014/12/23/2014-30011/minimal-manipulation-of-humancells-tissues-and-cellular--and-tissue-based-products-draft-guidance (accessed 25 June 2020).

7. OpenBiome. FMT preparation information. https://www.openbiome.org/treatment-information (accessed 2 October 2019)

8. ClinicalTrials.gov. Transfer of Healthy gut flora for Restoration of Intestinal microbiota Via Enema for Clinical Trials.gov. Transfer of Healthy gut flora for Restoration of Intestinal microbiota Via Enema for
patients in the rehabilitative phase of malnutrition (THRIVE). 22 March 2017. https://clinicaltrials.gov/ patients in the rehabilitative phase of malnutrition
$\mathrm{ct} 2 /$ show/NCT03087097 (accessed 25 June 2020).

9. South African Health Products Regulatory Authority. Guidance for the Submission of the South South African Health Products Regulatory Authority. Guidance for the Submission of the South
Africa CTD/eCTD: General \& Module 1. May 2019. sahpra.org.za/wp-content/uploads/2020/02/2.01Guidance_General_Module_1_May19_v6-1.pdf (accessed 25 June 2020).

10. Medicines and Related Substances Act 101 of 1965. https://www.sahpra.org.za/wp-content/ uploads/2020/02/Government_Gazette_Medicines_and_Devices_Act_Jun_2017-1.pdf (accessed 25 June 2020)

11. National Department of Health, South Africa. Guidelines for Good Practice in the Conduct of Clinical Trials with Human Participants in South Africa. Pretoria: NDoH, 2006. http://www.kznhealth.gov.za/ research/guideline2.pdf (accessed 30 October 2019).

12. Reitzer Pharmaceuticals (Pty) Ltd v Registrar of Medicines and Another 1998 (4) SA 660 (T) at 682-3.

13. Carapinha JL. Policy guidelines for risk-sharing agreements in South Africa. S Afr Fam Pract 2008;50(5):43-46. https://doi.org/10.1080/20786204.2008.10873760

14. South African Health Products Regulatory Authority. Biological Medicines Evaluation and Research Unit (BMERU). http://www.sahpra.org.za/biological-products/ (accessed 25 June 2020).

15. South African Health Products Regulatory Authority. Clinical Guideline. July 2019. https://www.sahpra. 5. South African Health Products Regulatory Authority. Clinical Guideline. July 2019. https://www.sahpra.
org.za/wp-content/uploads/2020/02/2.09_Clinical-Guideline_Jul19_v2-1.pdf (accessed 25 June 2020). org.za/wp-content/uploads/2020/02/2.09_Clinical-Guideline_Jul19_v2-1.pdf (accessed 25 June 2020).
6. ICH (International Council for Harmonisation of Technical Requirements for Pharmaceuticals for ICH (International Council for Harmonisation of Technica
Human Use). https://www.ich.org/ (accessed 25 June 2020).

17. European Medicines Agency. https://www.ema.europa.eu/en (accessed 25 June 2020).

18. South African Health Products Regulatory Authority. Complementary Medicines: Discipline-specific Safety and Efficacy. January 2020. http://www.sahpra.org.za/wp-content/uploads/2020/04/7.01_CMs SE_DS_Jan2020_v3_1..pdf (accessed 25 June 2020).

19. Khoruts A. Targeting the microbiome: From probiotics to fecal microbiota transplantation. Genome Med 2018;10:80-83. https://doi.org/10.1186/s13073-018-0592-8 